\title{
ORAL HEALTH PROFILE OF A GROUP OF MALAYSIAN DRUG ADDICTS
}

Sujak S.L. and Abdul-Kadir R. Oral health profile of a group of malaysian drug addicts. Annal Dent Univ Malaya 1999; 6: 4 - 7 .

\section{ABSTRACT}

A study was undertaken to identify the oral health status and treatment needs of 403 drug abusers enrolled in a drug rehabilitation center in Perak, Malaysia. The prevalence of dental caries was $97.0 \%$. Calculus was present in $82.1 \%$ of the dentate individuals, but only $14.6 \%$ had pockets greater than $3 \mathrm{~mm}$. The mean DMFT observed was 11.7, with missing teeth (MT=9.6) constituting the major component. Denture needs were high $(67.2 \%)$, but only $11.4 \%$ of individuals had prostheses.

Keywords: drug addicts; caries experience, periodontal diseases, denture needs.

\section{INTRODUCTION}

Drug abusers are often unconcerned with their personal hygiene. Their main concern in life is obtaining their next dose of drug. This phenomenon is prevalent irrespective of age, sex, race and nationality $(1,2)$. Studies performed in several countries have shown that the prevalence of dental caries and periodontal disease among these individuals are high (3-6). These findings have been attributed to unhealthy dietary habits and general oral neglect.

In Malaysia, drug addiction is a national problem since it can pose a security threat to the country's stability(7). According to the 1994 estimate, there were 28,756 registered substance abusers (new and repeat attenders) and seven percent of them were reported to be infected with the human immuno-deficiency virus(HIV)(8). The government in its effort to eradicate the problem, has responded by enrolling drug addicts into regional Rehabilitation Centers located throughout the country. While these centers provide regular medical health services to these individuals, dental care is provided only on a demand basis $(7,9)$. For an organized dental service to be planned, however, baseline information on the patients' oral health status and treatment needs is

Table 1 - Sample distribution

\begin{tabular}{|c|c|c|c|c|}
\hline \multirow[t]{2}{*}{ Age } & \multicolumn{3}{|c|}{$\begin{array}{c}\text { Ethnic Groups } \\
\text { n (\%) }\end{array}$} & \multirow[t]{2}{*}{$\begin{array}{l}\text { TOTAL } \\
\text { n (\%) }\end{array}$} \\
\hline & Malays & Chinese & Indians & \\
\hline$<25$ & $29(12.2)$ & $13(13.5)$ & $11(15.9)$ & $53 \quad(13.2)$ \\
\hline $25-29$ & $73(30.7)$ & $24(25.0)$ & $14(20.3)$ & $111 \quad(27.5)$ \\
\hline $30-34$ & $75(31.5)$ & $33(34.4)$ & $22(31.9)$ & $130 \quad(32.3)$ \\
\hline$>34$ & $61 \quad(25.6)$ & $26(27.1)$ & 22 (31.9) & $109 \quad(27.0)$ \\
\hline All & $238(100.0)$ & $96(100.0)$ & $69(100.0)$ & $403(100.0)$ \\
\hline
\end{tabular}

Sujak SL* and Abdul-Kadir $\mathrm{R}^{+}$

*Main Dental Clinic, Cahaya Suria, Kuala Lumpur, MALAYSIA

${ }^{+}$Department of Community Dentistry

University of Malaya,

Kuala Lumpur, MALAYSIA

\section{Correspondence Address:}

Dr Sharol Lail Sujak

Jabatan Pergigian Wilayah Persekutuan,

Tingkat 2, Bangunan Cahaya Suria

Jalan Tun Perak,

50050 Kuala Lumpur, MALAYSIA.

mandatory in order to determine the scope of oral health care that needs to be provided. This study was designed to provide an oral health profile of drug abusers in Malaysia.

\section{MATERIALS AND METHOD}

The study was performed at the Kamunting Detention Rehabilitation Center for drug abusers in Perak, the third largest center in Malaysia. The subjects were drug-addicts from all parts of the Malaysian Peninsula. The criteria for acceptance into the rehabilitation center was by court sentence( 9 ).

All the 403 male inmates at the centre participated in the study. The mean age of the group was 31.1 years with a range of 19 to 56 years. The years of drug-addiction ranged from one to twenty. Examination of the subjects was carried out in the dental clinic located at the detention centre. A cross-sectional profile of the dental health status of the inmates was assessed through clinical examination for dental caries, periodontal diseases and denture status. The dental survey form used was designed based on the criteria as described in the 1977 World Health Organization (WHO) Oral Health Surveys, Basic methods(10). One examiner conducted all examinations.

Data analysis was carried out using a statistical package on a microcomputer. Where appropriate t-test or a chi-square test was used to test for significance. The level of significance chosen was $\mathrm{p}=0.05$.

\section{RESULTS}

The distribution of the sample is as shown in Table 1. Malays formed the majority of all inmates (59.1\%) participating in the study, followed by the Chinese $(23.8 \%)$ and the Indians (17.1\%). Except for the $13.2 \%$ of subjects in the younger age group below 25 years old, almost equal proportion of the remaining subjects were in the other three age ranges. 
Table 2 - DMFT experience in a sample of 403 male drug addicts

\begin{tabular}{|c|cc|c|ccc|c|}
\hline Age & No examined & $\begin{array}{c}\text { Sample affected } \\
\mathrm{n}(\%)\end{array}$ & $\begin{array}{c}\text { Mean no. of teeth } \\
\text { present (s.d) }\end{array}$ & DT & MT & F T & DMFT(s.d) \\
\hline & & & & & & & \\
\hline 25 & 53 & $50(94.3)$ & $27.5(2.2)$ & 1.7 & 4.5 & 0.5 & $6.7(6.4)$ \\
$25-29$ & 111 & $106(95.5)$ & $25.7(4.6)$ & 1.8 & 7.0 & 0.6 & $9.3(5.5)$ \\
$30-34$ & 130 & $129(99.2)$ & $22.1(7.5)$ & 1.1 & 10.9 & 0.6 & $12.7(8.0)$ \\
$>34$ & 109 & $106(97.2)$ & $26.3(5.3)$ & 0.7 & 17.2 & 0.3 & $17.7(7.7)$ \\
\hline & 403 & $391(97.0)$ & $23.0(4.5)$ & 1.3 & 9.6 & 0.9 & $11.7(6.9)$ \\
\hline
\end{tabular}

Table 2 shows the caries experience of the 403 drug addicts in this study. Dental caries was found to affect $97 \%$ of all drug addicts examined. The mean DMFT score for all age groups was $11.7 \pm 6.9$ (s.d). Missing teeth comprised the bulk of the DMFT score $(\mathrm{MT}=9.6)$, with only 1.3 teeth found to be carious while 0.9 teeth were found to have been restored. The prevalence of dental caries was found to be consistently high across all age groups. However, the mean number of teeth affected was found to be lowest in those below 25 years old (DMFT = 6.7), while the highest DMFT of 17.7 was recorded for those over age 34 years old.

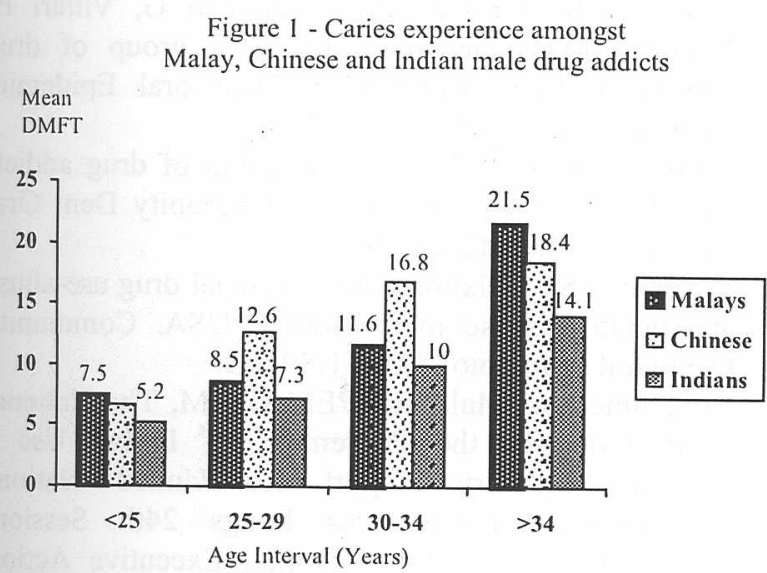

Table 3 - Distribution of calculus and pocket $>3 \mathrm{~mm}$ in 403 male drug addicts.

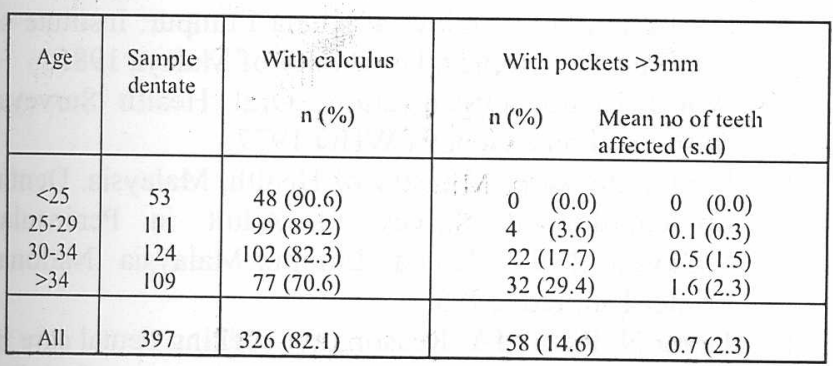

Figure 2 - Pattern of tooth loss

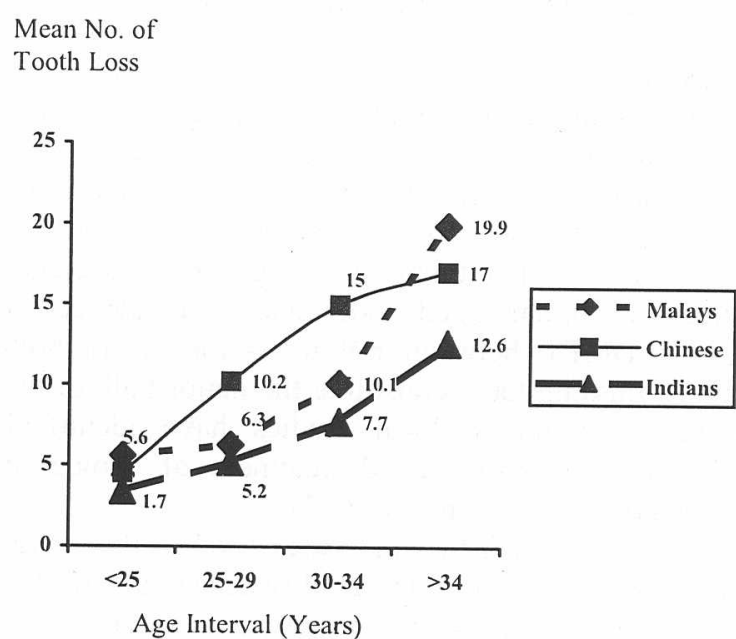

When comparing by ethnic groups, the Indians were found to have the lowest caries experience in all age groups (Figure 1). There was, however, slight difference in caries experience between the three ethnic groups in those 25 years and below. Between 25 to 34 years old, the Chinese had a significantly higher caries experience than either the Malays or Indians $(\mathrm{p}=0.05)$. After 35 years old, the Malays appeared to have the highest caries experience. In terms of tooth loss, however, after 29 years old both the Indians and Malays showed an increasing pattern while the rate appeared to have plateau amongst the Chinese (Figure 2).

Calculus was present in $82.1 \%$ of all dentate patients (Table 3). Of those with calculus, $67.7 \%$ were found to have gingivitis. In addition, only $14.6 \%$ of the sample examined were found to have pockets greater than $3 \mathrm{~mm}$. The proportion of those with pockets was observed to increase with age. A four to ten fold increase in prevalence was observed after the age of 30 years, when compared to those in the $25-29$ years age group. The mean number of teeth affected, however, was small. 
Table 4 - Distribution of subjects wearing or needing dentures.

\begin{tabular}{|c|c|c|c|c|c|c|}
\hline \multirow[t]{2}{*}{$\begin{array}{c}\text { Age } \\
\text { (Years) }\end{array}$} & \multirow[t]{2}{*}{ Sample size } & \multirow[t]{2}{*}{$\begin{array}{l}\text { With denture } \\
\text { n }(\%)\end{array}$} & \multicolumn{4}{|c|}{$\begin{array}{c}\text { Needing denture } \\
\mathrm{n}(\%)\end{array}$} \\
\hline & & & Partial & Full & Full/Partial & TOTAL \\
\hline$<25$ & 53 & $4 \quad(7.5)$ & 23 & 0 & 0 & $23(43.4)$ \\
\hline $25-29$ & 111 & $13(11.7)$ & 67 & 0 & 1 & 68 (61.3) \\
\hline $30-34$ & 130 & $22(16.9)$ & 82 & 3 & 9 & $94(72.3)$ \\
\hline$>34$ & 109 & $7(6.4)$ & 76 & 3 & 7 & $86(78.9)$ \\
\hline All & 403 & $46(11.4)$ & 248 & 6 & 17 & $271(67.2)$ \\
\hline
\end{tabular}

Although the need (78.6\%) for dental prostheses was, very high, but only $11.4 \%$ of the patients had dentures while $67.2 \%$ were found to need dentures (Table 4). Of those needing dentures, $95.1 \%$ required a partial denture, and $2.2 \%$ required full dentures. The remaining $6.3 \%$ of patients required both a partial denture and full denture. Results also suggested that even at younger age group (below 25 years old), 43.4\% needed dentures.

\section{DISCUSSION}

This study demonstrated that drug-addicts have a high caries prevalence, poor oral hygiene status and, poor periodontal health. The caries experience was found to be in accordance with other reported studies worldwide (4-6), and comparable to that found in the general Malaysian population of similar aged individuals (prevalence of $94.6 \%$, and DMFT between 6.9 to 14.2$)(11)$. In both populations, missing teeth constitute the major bulk of the DMFT score. Available local studies have identified extractions as the most quoted treatment of choice of patients attending these clinics $(12,13)$.

It is recognised that the index used in this study limits comparison of periodontal disease status of this group with the findings in the adult national study conducted in 1990. Nevertheless, it is interesting to note the similarity in the pattern of high prevalence for gingivitis and calculus among the drug addicts as that observed in the general population of similarly aged Malaysians (11). This finding is similar to those reported in other countries which used their general population as the reference groups $(6,14)$. Lack of proper personal hygiene, poor attitude and inadequate dental care practices amongst the drug addicts have been quoted as contributing factors.

It is also of interest to note that the prevalence of periodontal pockets is greater than $3 \mathrm{~mm}$ in this study. This implies that very few of those who had either calculus or gingivitis underwent further disease progression. This observation is consistent with the current understanding of the disease progression and severity (15).

This study also noted that in spite of a large number of patients requiring dentures, the percentage of those wearing them is small. The low percentage of denture wearers is perhaps in part due to the poor attitude of the addicts towards the importance of oral health. In addition, resource constraints have precluded drug addicts from being included in the priority groups eligible for receiving government sponsored dental care on a regular basis (16). This policy will require change because many of the individuals requiring dentures were in their early 20 's. It is imperative that oral health promotion programs be initiated and that substance abusers enrolled in rehabilitation and resocialization programs be targeted for dental care.

\section{REFERENCES}

1. Colon PG. Jr. Dental disease in the narcotic addiction. Oral Surg 1972; 33:905-10.

2. Rosenstein DI. Effect of long-term addiction to heroin on oral tissues. J Public Health Dent 1975; 35:118-22.

3. Molendijk B, Ter Horst G, Kasbergen M, Truin GJ, Mulder J. Dental health in Dutch drug addicts. Community Dental Oral Epidemiol 1996; 24:117-19.

4. Angelillo IF, Grasso GM, Sagliocco G, Villari P, D'Errico MM. Dental health in a group of drug addicts in Italy. Community Dent oral Epidemiol 1991; 19:36-37.

5. Scheutz F. Dental health in a group of drug addicts attending an addiction-clinic. Community Dent Oral Epidemiol 1984; 12:23-28.

6. Silverstein SJ. Relation between social drug use-abuse and dental disease in California, USA. Community Dent Oral Epidemiol 1973; 1:89-93.

7. Government of Malaysia. PEMADAM, The National Association for the Prevention of Dadah Use Malaysia Country Report for United Nations Commission on Narcotics Drugs 24th Session, Vienna. Kuala Lumpur: National Executive Action Unit, Cabinet Committee on Dadah, 1981.

8. Ministry of Health, Malaysia. Malaysia's Health: Technical Report of Director General of Health. Kuala Lumpur: Malaysia National Printer Limited, 1996.

9. Lee R.L.M. The social processes of drug use and rehabilitation in Malaysia. Kuala Lumpur: Institute of Postgraduate Studies, University of Malaya 1986.

10. World Health Organization. Oral Health Surveys. Basic methods. Geneva WHO 1977.

11. Dental Division, Ministry of Health, Malaysia. Dental Epidemiological Survey of Adult in Peninsular Malaysia 1990. Kuala Lumpur:Malaysia National Printer Limited, 1993.

12. Jaafar N, Razak IA. Reasons for seeking dental care in a Malaysian urban adult population: An analysis by sex and ethnic group. Community Dent Oral Epidemiol 1988; 16:75-78. 
13. Raghunandanan KP. An investigation of patterns of tooth loss in young and middle aged adults in Sandakan, Sabah. University of Malaya, Kuala Lumpur: MCD Research Report, 1995.

14. Shapiro S., Pollack BR, Gallant D. Periodontal disease in narcotic addicts. J Dent Res 1970; 49:1556.
15. Goodson JM, Tanner ACR, Haffajee AD et al. Pattern of progression and regression of advanced destructive periodontal disease. J Clin Periodontol 1982; 9:47281.

16. Dental Division Ministry of Health, Malaysia. Dental Services Malaysia. Kuala Lumpur: Malaysia National Printer Limited, 1991 